\title{
Nitric Oxide Delivery by Neonatal Noninvasive Respiratory Support Devices
}

\author{
Robert M DiBlasi RRT-NPS FAARC, Donna Dupras RRT-NPS, \\ Christine Kearney RRT-NPS, Eddie Costa Jr RRT, and Jeffrey L Griebel RRT
}

\begin{abstract}
BACKGROUND: Inhaled nitric oxide (INO) has been used with heated and humidified high-flow nasal cannula (HFNC), nasal CPAP and several forms of noninvasive ventilation (NIV). This study was designed to evaluate the delivered dose of $\mathrm{INO}$, level of $\mathrm{NO}_{2}$ generation, and effect of net gas delivery (addition of INO to the ventilator circuit - gas removed for sampling) on lung pressure at different NO doses during noninvasive respiratory support. METHODS: An infant lung model was supported with the different noninvasive modes during INO therapy. $\mathrm{NO}$ and $\mathrm{NO}_{2}$ were measured from within the patient circuit of the noninvasive devices and simulated neonatal trachea at several NO levels. Lung pressures were compared with and without INO and at several INO settings. RESULTS: Accuracy of NO delivery was determined to be within the stated accuracy by the manufacturer with nasal CPAP and NIV, but accuracy was compromised during HFNC. INO and $\mathrm{NO}_{2}$ measured by the INOmax DS delivered dose of $\mathrm{NO}$ or formation of $\mathrm{NO}_{2}$ across all types of neonatal noninvasive respiratory support. Tracheal $\mathrm{NO}_{2}$ levels were $<1.5 \mathrm{ppm}$ with all forms of noninvasive support, except nasal intermittent mandatory ventilation at $40 \mathrm{ppm}$ INO. Lung model mean airway pressures were mildly affected by gas sampling/delivery during combined INO therapy/HFNC at certain flows but remained stable with all other forms of noninvasive support. CONCLUSIONS: Clinicians cannot always assume that the set INO level results in a similar lung dose when using all forms of neonatal noninvasive support. Clinical decisions regarding ways to improve INO delivery may need to include changing settings or placing patients on a different form of noninvasive support. The $\mathrm{NO}_{2}$ level delivered to the patient could be greater than the value recorded by the INO delivery system. Key words: inhaled nitric oxide; heated and humidified high-flow nasal cannula; noninvasive ventilation; nasal CPAP. [Respir Care 2015;60(2):219-230. ( 2015 Daedalus Enterprises]
\end{abstract}

\section{Introduction}

Inhaled nitric oxide (INO) is a potent pulmonary vasodilator drug that is approved for use in term and near-term infants ( $>34$ weeks of gestation) with acute hypoxic respiratory failure associated with pulmonary hypertension. ${ }^{1}$ The vast majority of INO research in the neonatal popu-

Mr DiBlasi, Ms Dupras, and Ms Kearney are affiliated with the Seattle Children's Hospital, Seattle, Washington. Mr DiBlasi is also affiliated with the Center for Developmental Therapeutics, Seattle Children's Hospital Research Institute, Seattle, Washington. Mr Costa and Mr Griebel are employed by Ikaria, Hampton, New Jersey.

This study was funded in part by Ikaria through donation of the drug and delivery system. The authors have disclosed no other conflicts of interest. lation has been done in subjects receiving conventional or high-frequency mechanical ventilation. Due to the improved understanding of the role of invasive ventilation in the initiation of lung injury ${ }^{2,3}$ and potential for increasing pulmonary vascular resistance,$^{4}$ there has been increased interest in combining noninvasive ventilation (NIV) with INO therapy.

\footnotetext{
Correspondence: Robert M DiBlasi RRT-NPS FAARC, Center for Developmental Therapeutics, Seattle Children's Hospital Research Institute, 1900 Ninth Avenue North, Seattle, WA 98101. E-mail: robert.diblasi@ seattlechildrens.org.
}

DOI: $10.4187 /$ respcare. 03278 
Currently, there is only one FDA-cleared delivery device available that maintains a consistent delivered INO dose regardless of the patient gas flow. The device has been validated by the manufacturer to be used with several neonatal noninvasive respiratory support devices, including heated and humidified high-flow nasal cannula (HFNC), nasal CPAP (nasal CPAP), and several ventilators that have been used for NIV. There have been sporadic reports about the combined clinical use of INO therapy delivered through noninvasive devices. Kinsella et $\mathrm{al}^{5}$ first described noninvasive INO delivery through a nasal cannula following surgical repair in a select group of subjects with congenital diaphragmatic hernia and late pulmonary hypertension. There have also been a series of clinical studies describing INO/CPAP in premature infants as part of a treatment strategy, and there were no reported safety concerns in these trials. ${ }^{6-8}$

Factors that are known to affect the concentration and fluctuation in the inspired concentration of INO include the INO delivery system, respiratory support device type, settings and mode, circuit design, site of delivery of INO, size of mixing chamber (if any) in the patient circuit, concentration of inspired oxygen, and site and method of INO monitoring. ${ }^{9}$ When INO is delivered during conventional or high-frequency oscillatory ventilation via an endotracheal tube, it can be assumed that the preset INO dose is similar to what the patient receives in the lung. ${ }^{10,11}$ However, little is known about the compatibility, accuracy, and safety of INO delivery using the array of available noninvasive strategies.

Nitrogen dioxide $\left(\mathrm{NO}_{2}\right)$ is a toxic by-product that forms when $\mathrm{NO}$ and $\mathrm{O}_{2}$ gases are allowed to mix. This chemical reaction can take place in the gas delivery system or noninvasive delivery device, the airway interface, and the lungs. ${ }^{1}$ Factors influencing the generation of $\mathrm{NO}_{2}$ include $\mathrm{F}_{\mathrm{IO}_{2}}$, dose of INO, and dwell time for INO and oxygen. ${ }^{12}$ $\mathrm{NO}_{2}$ accumulation is more likely to form when using high $\mathrm{F}_{\mathrm{IO}_{2}}$ in combination with high INO concentrations. It is unclear whether the complicated physical gas flow pathways of neonatal noninvasive support or the upper airway fosters an environment wherein toxic levels of $\mathrm{NO}_{2}$ can accumulate and be inhaled into the lungs. Additionally, INO delivery systems continuously sample gas, and it is unknown whether the subtraction of gas sampling from the patient circuit or addition of INO gas can affect the patient's mean airway pressure levels. As such, clinicians may be hesitant to use INO therapy in conjunction with noninvasive delivery devices.

This study was designed to evaluate the delivered dose of INO, level of $\mathrm{NO}_{2}$ generation, and effect of sampling on lung parameters at different $\mathrm{NO}$ doses in a realistic, spontaneously breathing, neonatal lung model using noninvasive respiratory support. We hypothesized that there would be no differences between: (1) tracheal INO and the preset

\section{QUICK LOOK}

\section{Current knowledge}

Inhaled nitric oxide (INO) is a selective pulmonary vasodilator used to treat acute hypoxemic respiratory failure associated with pulmonary hypertension during mechanical ventilation. Delivery of nitric oxide during noninvasive ventilation (NIV), including high-flow nasal oxygen, has increased with the recognition of the importance of avoiding intubation in infants.

\section{What this paper contributes to our knowledge}

In an infant lung model, INO delivery with a commercially available device was accurate with both nasal CPAP and NIV. During high-flow nasal oxygen via cannula, set and delivered nitric oxide concentrations were significantly different. Nitrogen dioxide formation was $<1.5 \mathrm{ppm}$ in all conditions.

INO level on the nitric oxide delivery system, (2) $\mathrm{NO}_{2}$ measured on the INO delivery device and tracheal $\mathrm{NO}_{2}$; and (3) mean airway pressure in the lung model at baseline (no INO therapy) and at multiple INO doses.

\section{Methods}

Ikaria (Hampton, New Jersey) reviewed the study protocol to provide technical support where required. The research was conducted by $\mathrm{RMD}, \mathrm{DD}$, and $\mathrm{CK}$ in the laboratory of RMD at Seattle Children's Hospital in Washington. All data collection, data analysis, and interpretation of data were done by RMD, DD, and CK. EC and JLG, both employees of Ikaria, were present for the study and reviewed the manuscript.

\section{Nasal Airway/Lung Model}

The neonatal test lung (ASL 5000, IngMar Medical, Pittsburgh, Pennsylvania) has a screw drive-controlled piston and uses a mathematical model of the equation of motion of the human respiratory system to simulate disease-specific pulmonary mechanics. The lung model was configured to represent the pulmonary mechanics of a term newborn infant (compliance of $2 \mathrm{~mL} / \mathrm{cm} \mathrm{H}_{2} \mathrm{O}$ and resistance of $\left.25 \mathrm{~cm} \mathrm{H}_{2} \mathrm{O} / \mathrm{L} / \mathrm{s}\right) .{ }^{13}$ The lung model was made to breathe spontaneously by setting a simulated pleural pressure profile of $12 \mathrm{~cm} \mathrm{H}_{2} \mathrm{O}$, yielding a tidal volume of $\sim 24 \mathrm{~mL}$ with a rate of 40 breaths $/ \mathrm{min}$. An anatomically accurate neonatal nasal/upper airway model, scaled to a 3.0-kg infant, was attached to the lung model via a simu- 


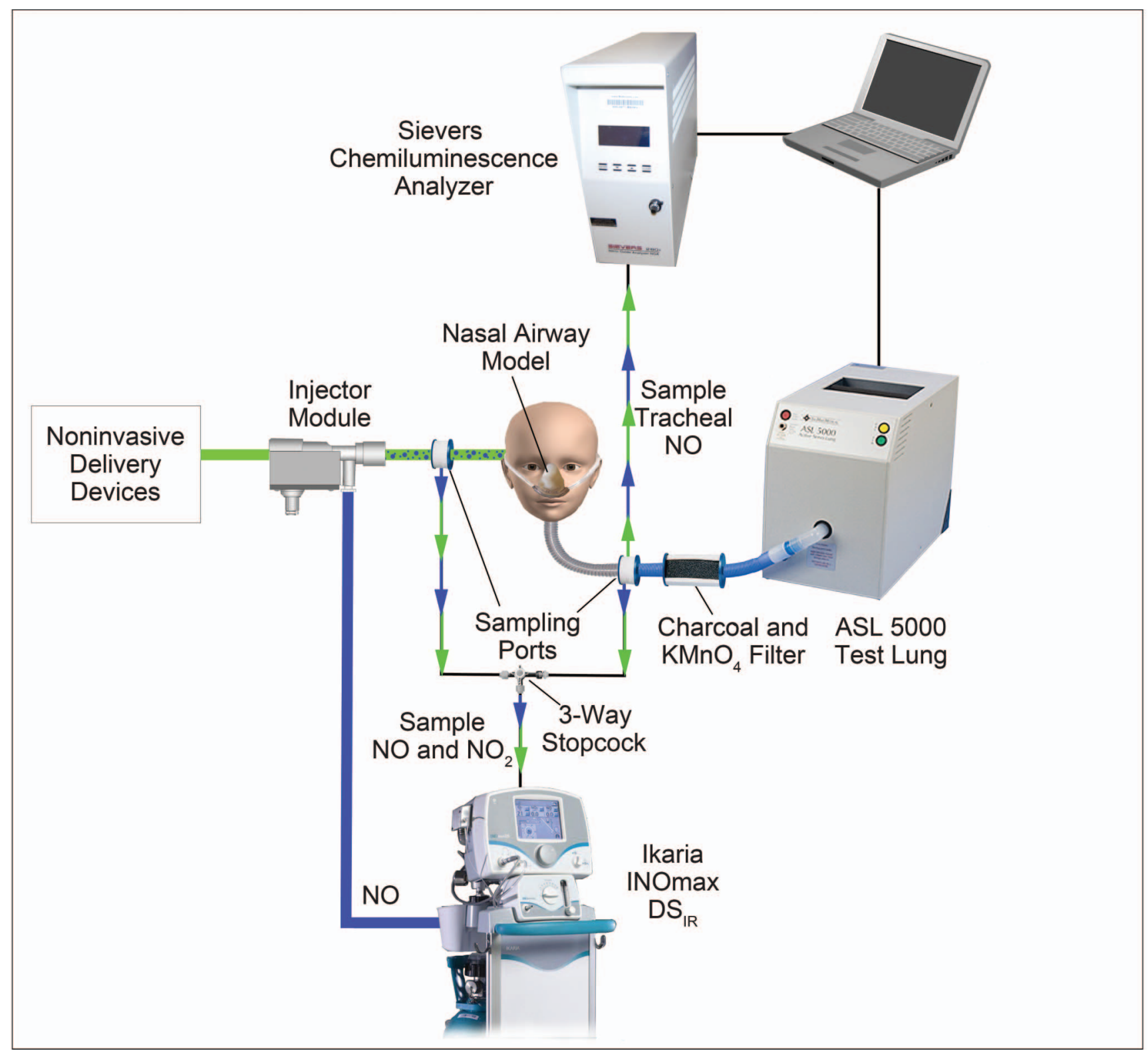

Fig. 1. Experimental setup.

lated trachea $(4.0-\mathrm{mm}$ inner diameter endotracheal tube, $6 \mathrm{~cm}$ in length). A similar neonatal nasal airway model has been described in detail elsewhere. ${ }^{14}$ A potassium permanganate $\left(\mathrm{KMnO}_{4}\right) /$ charcoal filter was placed at the inlet of the lung model to scrub INO and remove any exhaled $\mathrm{NO} / \mathrm{NO}_{2}$ in the gas exiting the lung model to eliminate rebreathing of NO so that the simulated tracheal gas concentrations would consist of inhaled $\mathrm{NO}$ and $\mathrm{NO}_{2}$ only. ${ }^{15,16}$ Figure 1 shows a schematic of the experimental setup. Before and following testing, the efficacy of the $\mathrm{KMnO}_{4}$ filter was evaluated by measuring the $\mathrm{NO}$ and $\mathrm{NO}_{2}$ distal to the filter at a flow of $6 \mathrm{~L} / \mathrm{min}$ with $\mathrm{F}_{\mathrm{IO}_{2}}$ of 1.0 and INO of 5,20 , and 40 ppm.

\section{Noninvasive Delivery Devices}

We chose to test an array of noninvasive delivery devices that are currently being used in neonatal ICUs within the United States. These included 3 different constantflow, constant-pressure nasal CPAP devices; one constantflow, variable-pressure nasal CPAP device; one HFNC (Fisher \& Paykel Healthcare, Auckland, New Zealand); and 2 NIV devices (sigh positive airway pressure [SiPAP[, CareFusion, San Diego, CA; and nasal intermittent mandatory ventilation [N-IMV]). Table 1 provides a summary of the different delivery devices, mechanism of pressure generation, and settings. Each device uses inherently dif- 
Table 1. Noninvasive Delivery Device Settings and Operational Characteristics

\begin{tabular}{|c|c|c|c|c|}
\hline Brand & Type & Flow/Pressure (Other Settings) & $\begin{array}{l}\mathrm{F}_{\mathrm{IO}_{2}} \\
\text { Setting }\end{array}$ & Pressure/Flow Dynamics \\
\hline Vapotherm HFNC & HFNC & $2,4,6,8 \mathrm{~L} / \mathrm{min}$ & 1.0 & Variable pressure/constant flow \\
\hline CareFusion Infant Flow & Nasal CPAP & $5 \mathrm{~cm} \mathrm{H}_{2} \mathrm{O}$ & 1.0 & Variable flow/constant pressure \\
\hline CareFusion AirLife & Nasal CPAP & $5 \mathrm{~cm} \mathrm{H}_{2} \mathrm{O}$ & 1.0 & Variable flow/constant pressure \\
\hline Hamilton Arabella & Nasal CPAP & $5 \mathrm{~cm} \mathrm{H}_{2} \mathrm{O}$ & 1.0 & Variable flow/constant pressure \\
\hline Fisher \& Paykel bubble CPAP & Nasal CPAP & $5 \mathrm{~cm} \mathrm{H}_{2} \mathrm{O}$ & 1.0 & Variable pressure/constant flow \\
\hline CareFusion SiPAP & $\begin{array}{l}\text { Nasal sigh positive } \\
\text { airway pressure }\end{array}$ & $\begin{array}{l}8 / 4 \mathrm{~cm} \mathrm{H}_{2} \mathrm{O} \text {; breathing frequency } \\
20 \text { breaths/min, inspiratory time } 0.4 \mathrm{~s}\end{array}$ & 1.0 & Variable pressure/constant flow \\
\hline CareFusion Avea & N-IMV & $\begin{array}{l}20 / 5 \mathrm{~cm} \mathrm{H}_{2} \mathrm{O} \text { breathing frequency } \\
20 \mathrm{breaths} / \mathrm{min} \text {, inspiratory time } 1 \mathrm{~s}\end{array}$ & 1.0 & Variable pressure/constant flow \\
\hline
\end{tabular}

HFNC $=$ high-flow nasal cannula

$\mathrm{N}-\mathrm{IMV}=$ nasal intermittent mandatory ventilation

ferent mechanisms to generate pressure. These have been described in greater detail elsewhere. ${ }^{17}$ Many of these devices use a monophasic flow through a common circuit configuration and/or provide pressure through complex physical pathways. The HFNC provides a continuous monophasic flow to the nasal airway during the respiratory cycle, and patient exhalation occurs through a leak in the naris or oropharynx. The Infant Flow nasal CPAP (CareFusion), SiPAP, and Arabella (Hamilton Medical, Reno Nevada) devices use a fluidic flip-type control, whereas the AirLife (CareFusion) uses vortices to maintain pressure and provide exhalation. ${ }^{17}$ The bubble CPAP system (Fisher \& Paykel Healthcare) uses a piece of tubing placed in a water column that provides pressure proportional to the depth below the water surface, and the gas exiting into the water column results in noisy, small-amplitude, high-frequency pressure oscillations. During NIMV, variable flow from the ventilator (Avea, CareFusion) provides inspiratory flow and pressure through a dual-limb circuit, and an active exhalation valve located back at the ventilator maintains PEEP. All noninvasive devices were set up according to the manufacturer's recommendations ${ }^{18}$ with settings that are commonly used in current clinical practice (Table 1). Not all devices tested have been validated by the manufacturer; clinicians should refer to the Ikaria INOmax $\mathrm{DS}_{\mathrm{IR}}$ operation manual for a list of validated devices. In all testing conditions except HFNC, occlusive short bi-nasal prongs were used. The prong size was selected to ensure a snug fit into the nasal airway opening to minimize leak. The non-occlusive prongs used with the HFNC device were chosen so that the external diameter of the prongs occupied approximately one half of the internal diameter of the naris. Customary heated and humidified gases were used with a Fisher \& Paykel MR730 heated humidifier. All devices were set to $\mathrm{F}_{\mathrm{IO}_{2}}$ of 1.0 to maximize $\mathrm{NO}_{2}$ generation during testing.

\section{INO Delivery System and Chemiluminescence Analyzer}

The INOmax $\mathrm{DS}_{\mathrm{IR}}$ was used to deliver the INO for all test conditions. The delivery system is capable of delivering a dose of $0.1-80 \mathrm{ppm}$ and uses an injector module containing a mass hot film sensor to continuously monitor inspired gas flow, injecting proportional amounts of INOmax ( $800 \mathrm{ppm} \mathrm{NO}$ with balanced $\mathrm{N}_{2}$ ) source gas to maintain a constant delivered dose. The INOmax $\mathrm{DS}_{\mathrm{IR}}$ adds $\mathrm{NO} / \mathrm{N}_{2}$ gas to the breathing circuit in proportion to the NO setting and gas flow output of each device. For example, at an $80 \mathrm{ppm} \mathrm{NO}$ setting (the maximum NO setting with an $800 \mathrm{ppm}$ NO cylinder concentration), the INOmax $\mathrm{DS}_{\mathrm{IR}}$ adds $10 \%$ more gas to that delivered by the ventilator and proportionally less for lower NO settings. ${ }^{18}$

The INOmax $\mathrm{DS}_{\mathrm{IR}}$ has a built-in gas analysis system capable of continuously monitoring INO, $\mathrm{NO}_{2}$, and $\mathrm{F}_{\mathrm{IO}_{2}}$ using electrochemical cells for each gas. The monitoring sample system removes gas at a rate of $230 \mathrm{~mL} / \mathrm{min}$. Monitored values are updated every $100 \mathrm{~ms}$ using a 10-sample rolling average, and the on-screen display is updated every second. The INOmax $\mathrm{DS}_{\mathrm{IR}}$ was calibrated, and performance was verified according to the manufacturer's recommendations. ${ }^{18}$ Additional NO gas analysis was performed within the simulated neonatal trachea using a fast-response chemiluminescence analyzer (Sievers NOA 280i, GE Healthcare, Madison, Wisconsin). Chemiluminescent NO measurement is more sensitive and reproducible than electrochemical cells and is considered the accepted standard for measuring NO. ${ }^{19,20}$ The monitor is capable of analyzing NO samples of $<1.0-500,000 \mathrm{ppb}$ $(500 \mathrm{ppm})$ with a $67-\mathrm{ms}$ response time. Gas samples are withdrawn at $\sim 200 \mathrm{~mL} / \mathrm{min}$. Data from the monitor was continuously uploaded to a computer and recorded at 10 samples/s. The INOmax $\mathrm{DS}_{\mathrm{IR}}$, sample system tubing, and 


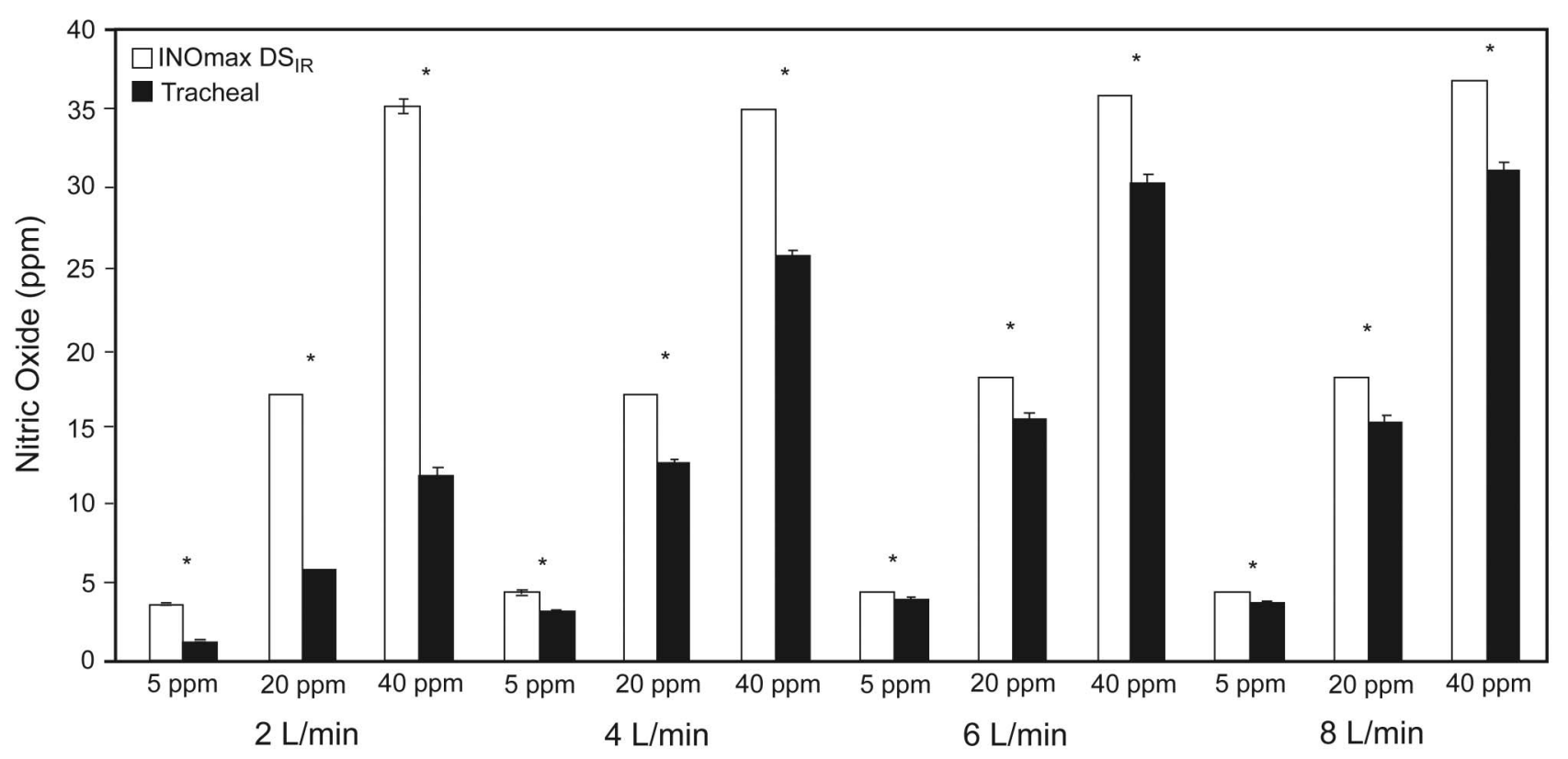

Nitric oxide settings and HFNC flow

Fig. 2. Nitric oxide levels with heated and humidified high-flow nasal cannula (HFNC). Data are shown as mean \pm SD. ${ }^{*} P<.001$.

injector module were affixed to the respective gas outlets or inspiratory side of each device. The sampling port was configured following manufacturers' recommendations. ${ }^{18}$ $\mathrm{NO}_{2}$ levels were monitored using the INOmax DS ${ }_{\text {IR }}$ sample system and a 3-way stopcock to switch between the sampling locations on the inspiratory circuit of the noninvasive devices and simulated trachea (see Fig. 1). Tracheal $\mathrm{NO}_{2}$ measurements were necessary to determine whether additional mixing of gases in the patient circuit, nasal airway interface, nasal airway model, and trachea created elevated levels of the by-product.

\section{Experimental Conditions}

All noninvasive respiratory support devices were attached to the spontaneously breathing lung model via the nasal airway, and following a 5-min stabilization period, breath-by-breath tracheal NO levels were measured using the Sievers chemiluminescence analyzer while NO and $\mathrm{NO}_{2}$ from the patient circuit were recorded from the INOmax $\mathrm{DS}_{\mathrm{IR}}$ monitor onto a spreadsheet for $1 \mathrm{~min}$ at 0 (baseline), 5, 20, and $40 \mathrm{ppm}$. The baseline measurements were obtained without the INOmax $\mathrm{DS}_{\mathrm{IR}}$ sampling adapter in-line. Mean airway pressure measurements were made from within the ASL 5000 (version 3.2) for $1 \mathrm{~min}$ at each of the testing conditions. Data were reduced from the ASL software to a spreadsheet (Excel, Microsoft, Redmond, Washington). Following this testing, the stopcock was turned (see Fig. 1), and tracheal $\mathrm{NO}_{2}$ was measured in the simulated trachea (before the $\mathrm{KMnO}_{4} /$ charcoal filter) using the INOmax $\mathrm{DS}_{\mathrm{IR}}$ for $1 \mathrm{~min}$, and breath-by-breath data were recorded on a spreadsheet.

\section{Data Analysis}

Differences in the preset INO level and mean tracheal NO measurements $(n=20)$ at each INO setting for each device were compared using a one-sample $t$ test. Accuracy between the preset INO level and tracheal NO measurements were determined by calculating accuracy: $\%$ error $=($ tracheal $\mathrm{NO}-$ preset INO level)/preset INO level $\times$ 100.

We determined differences a priori between the set INO level and mean delivered tracheal NO as $P<.05$, but considered anything $>20 \%$ or $\pm 2 \mathrm{ppm}$ (whichever is greater) to be outside the manufacturer's specified accuracy for the INOmax $\mathrm{DS}_{\mathrm{IR}}$. The stated accuracy of the chemiluminescence analyzer is $\pm 5 \%$. Differences in mean values of measured INO concentration on the INOmax $\mathrm{DS}_{\mathrm{IR}}$ and the tracheal $\mathrm{NO}$ were compared using a paired $t$ test, whereas differences in mean values of $\mathrm{NO}_{2}$ measurements from the patient circuit and simulated trachea were compared using an independent $t$ test. We also determined testing conditions that rendered tracheal $\mathrm{NO}_{2}$ levels of $>1.5 \mathrm{ppm}$ as potentially toxic.

Differences in mean airway pressure between 0 (baseline), 5, 20 and $40 \mathrm{ppm}$ were compared using one-way analysis of variance with Tukey post hoc testing. We de- 
Table 2. Accuracy Between Preset INO Level and Mean Tracheal NO Level

\begin{tabular}{|c|c|c|c|c|c|c|c|c|c|c|c|c|}
\hline \multirow[b]{3}{*}{ INO setting (ppm) } & \multicolumn{12}{|c|}{ HFNC } \\
\hline & \multicolumn{3}{|c|}{$2 \mathrm{~L}$} & \multicolumn{3}{|c|}{$4 \mathrm{~L}$} & \multicolumn{3}{|c|}{$6 \mathrm{~L}$} & \multicolumn{3}{|c|}{$8 \mathrm{~L}$} \\
\hline & 5 & 20 & 40 & 5 & 20 & 40 & 5 & 20 & 40 & 5 & 20 & 40 \\
\hline Error, \% & -75.25 & -70.72 & -70.23 & -37.30 & -36.51 & -35.52 & -21.45 & -22.60 & -23.96 & -25.30 & -23.50 & -22.01 \\
\hline
\end{tabular}

\begin{tabular}{|c|c|c|c|c|c|c|c|c|c|c|c|c|}
\hline \multirow[b]{3}{*}{ INO setting (ppm) } & \multicolumn{12}{|c|}{ Nasal CPAP Device } \\
\hline & \multicolumn{3}{|c|}{ Infant Flow Nasal CPAP } & \multicolumn{3}{|c|}{ AirLife Nasal CPAP } & \multicolumn{3}{|c|}{ Arabella Nasal CPAP } & \multicolumn{3}{|c|}{ Bubble Nasal CPAP } \\
\hline & 5 & 20 & 40 & 5 & 20 & 40 & 5 & 20 & 40 & 5 & 20 & 40 \\
\hline Error, \% & -9.80 & -15.35 & -12.95 & -13.40 & -17.90 & -17.88 & -6.40 & -11.80 & -10.90 & -4.60 & -9.70 & -9.13 \\
\hline
\end{tabular}

\begin{tabular}{|c|c|c|c|c|c|c|}
\hline \multirow[b]{3}{*}{ INO setting (ppm) } & \multicolumn{6}{|c|}{ NIV Device } \\
\hline & \multicolumn{3}{|c|}{ Infant Flow Nasal SiPAP } & \multicolumn{3}{|c|}{ N-IMV } \\
\hline & 5 & 20 & 40 & 5 & 20 & 40 \\
\hline Error, \% & -9.40 & -15.95 & -14.43 & -19.60 & -13.60 & -18.60 \\
\hline
\end{tabular}

$\overline{\text { Accuracy between the }}$ preset INO level and tracheal NO measurements was determined by calculating accuracy: $\%$ error $=($ tracheal NO - preset INO level $) /$ preset INO level $\times 100$ $\mathrm{INO}=$ inhaled nitric oxide

HFNC $=$ high-flow nasal cannula

SiPAP $=$ sigh positive airway pressure

$\mathrm{N}-\mathrm{IMV}=$ nasal intermittent mandatory ventilation

termined differences a priori in mean values for mean airway pressure in the lung model between 0 (baseline), 5, 20 and $40 \mathrm{ppm}$ as $P<.05$. These differences were also calculated: $\%$ change from baseline $=$ (measurement - baseline)/baseline $\times 100$, where baseline is the pressure measurement without $\mathrm{NO}$ or sampling from the INOmax $\mathrm{DS}_{\mathrm{IR}}$, and measurement is the pressure at 5, 20, and 40 ppm NO.

\section{Results}

\section{Efficacy of the $\mathrm{KMnO}_{4}$ Filter}

$\mathrm{NO}$ and $\mathrm{NO}_{2}$ levels were $<0.1$ ppm during the $\mathrm{KMnO}_{4}$ testing when $\mathrm{NO}$ was set at 5,20 , and $40 \mathrm{ppm}$ before and following the experiment, suggesting that $\mathrm{KMnO}_{4}$ effectively eliminated $\mathrm{NO}$ and $\mathrm{NO}_{2}$.

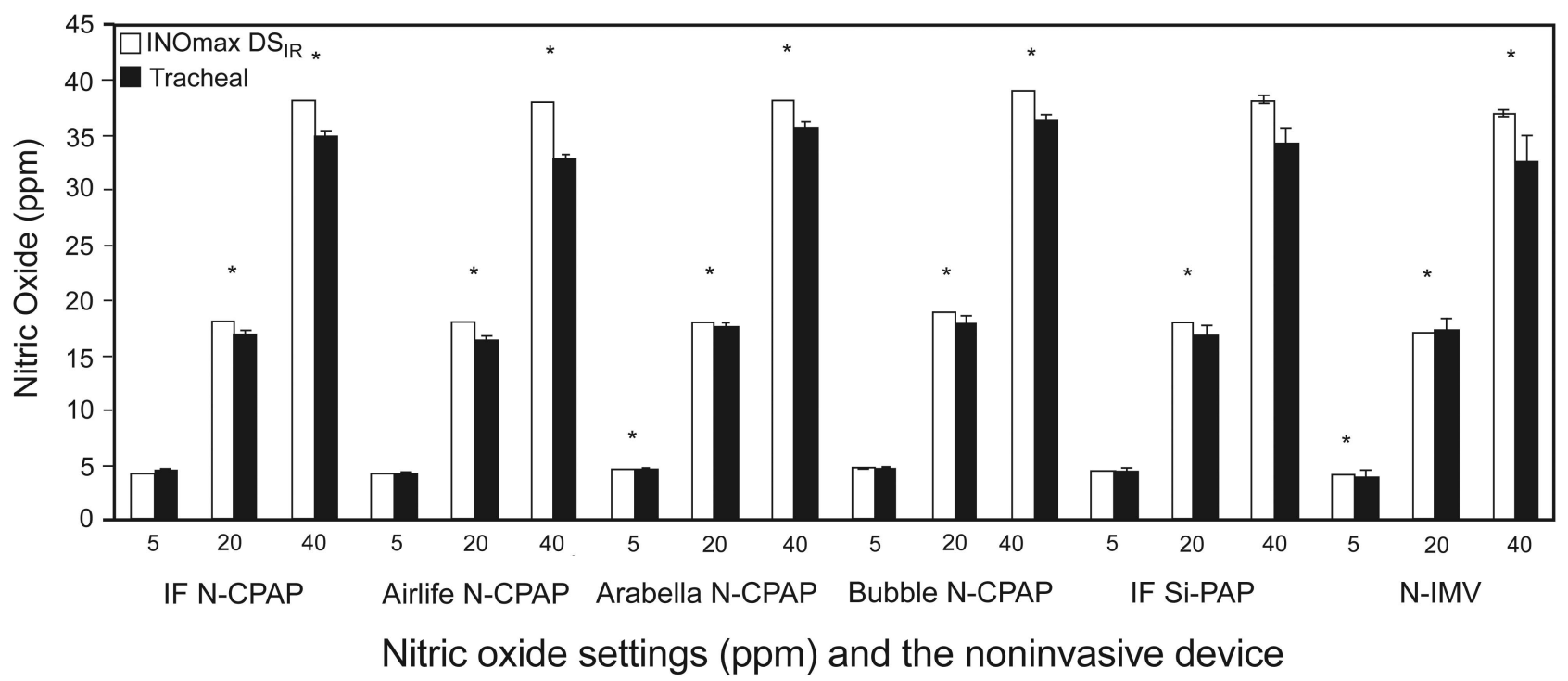

Fig. 3. Nitric oxide levels with nasal CPAP (N-CPAP) and noninvasive ventilation devices. Data are shown as mean \pm SD. ${ }^{*} P<.001$. IF = Infant Flow; Si-PAP = sigh positive airway pressure; N-IMV = nasal intermittent mandatory ventilation. 


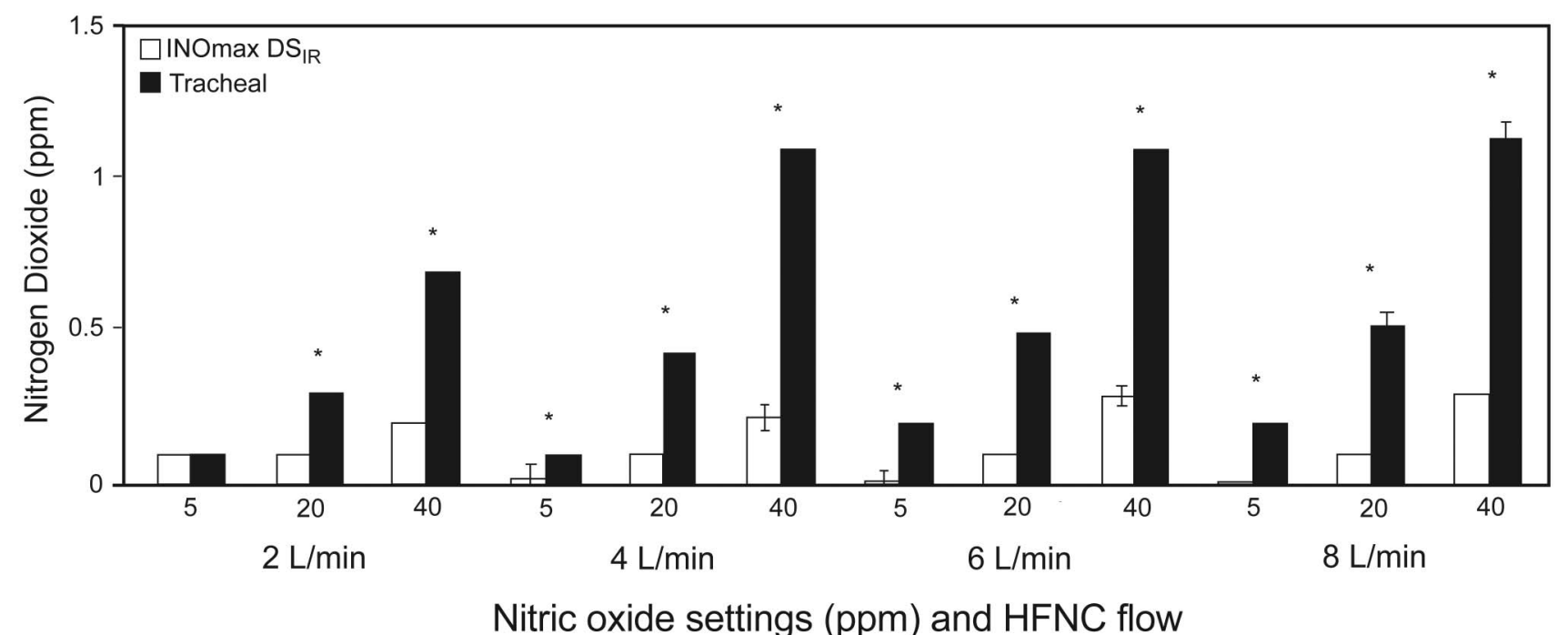

Fig. 4. Nitrogen dioxide levels with heated and humidified high-flow nasal cannula (HFNC). Data are shown as mean \pm SD. ${ }^{\star} P<.001$.

\section{Nitric Oxide Delivery}

Measured tracheal NO levels were lower than the preset NO level on the INOmax $\mathrm{DS}_{\mathrm{IR}}$ for all test conditions during HFNC $(P<.05)$ (Fig. 2). The disparity between the measured tracheal NO levels and the preset $\mathrm{NO}$ value were outside the manufacturer's specified accuracy $(>20 \%)$ for the INOmax $\mathrm{DS}_{\mathrm{IR}}$ at all testing conditions during HFNC (Table 2). The NO levels measured by the INOmax DS were greater than the tracheal NO levels under all testing conditions during HFNC $(P<.05)$. Overall, increasing the flow above $4 \mathrm{~L} / \mathrm{min}$ not only resulted in less disparity between the set INO and tracheal NO levels during HFNC, but the tracheal NO levels more closely reflected the set NO level on the INOmax $\mathrm{DS}_{\mathrm{IR}}$.

Measured tracheal NO levels were lower than the preset INO level on the INOmax $\mathrm{DS}_{\mathrm{IR}}$ under every testing conditions for all forms of nasal CPAP and NIV $(P<.05)$ (Fig. 3). The measured tracheal NO levels and the preset NO value were all within $20 \%$ under all testing conditions during nasal CPAP and NIV, which is within the specified accuracy for the INOmax $\mathrm{DS}_{\mathrm{IR}}$. The percent errors between the preset INO level and tracheal NO for nasal CPAP and NIV devices are reported in Table 2. The NO levels measured by the INOmax $\mathrm{DS}_{\mathrm{IR}}$ were different from the tracheal NO levels under all testing conditions during nasal CPAP and NIV $(P<.05)$, except for bubble CPAP at $5 \mathrm{ppm}(P=.62)$, Infant Flow nasal CPAP at $5 \mathrm{ppm}$ $(P=.08)$, and AirLife nasal CPAP at $5 \mathrm{ppm}(P=.08)$.

\section{Nitrogen Dioxide Formation}

Tracheal $\mathrm{NO}_{2}$ levels were greater than those measured in the patient circuit under all HFNC testing conditions
$(P<.05)$, except for HFNC $(2 \mathrm{~L} / \mathrm{min})$ at $5 \mathrm{ppm} \mathrm{NO}$ $(P=1.0)$ (Fig. 4). There were no $\mathrm{NO}_{2}$ levels $>1.5 \mathrm{ppm}$ measured during HFNC, regardless of flow setting or NO dose being used.

Tracheal $\mathrm{NO}_{2}$ levels were greater than measured $\mathrm{NO}_{2}$ levels made from within the patient circuit during nasal CPAP and NIV $(P<.05)$, except for bubble CPAP at 5 ppm NO $(P=1.0)$ (Fig. 5). Tracheal $\mathrm{NO}_{2}$ levels were well within a clinically acceptable range $(<1.5 \mathrm{ppm})$ with all devices and at all NO levels, except for N-IMV at $40 \mathrm{ppm}$, where the tracheal $\mathrm{NO}_{2}$ level was $>2 \mathrm{ppm}$.

\section{Lung Model Pressures}

There were significant differences in mean airway pressure between baseline and the different NO levels for all HFNC testing conditions $(P<.05)$ (Fig. 6). Differences between mean airway pressure at baseline and at 5,20, and $40 \mathrm{ppm}$ during HFNC were within $10 \%$ for all testing, except for HFNC: $2 \mathrm{~L} / \mathrm{min}$ at $5 \mathrm{ppm}(-13.04 \%), 2 \mathrm{~L} / \mathrm{min}$ at $20 \mathrm{ppm}(-10.43 \%), 4 \mathrm{~L} / \mathrm{min}$ at $5 \mathrm{ppm}(-21.36 \%)$, $4 \mathrm{~L} / \mathrm{min}$ at $20 \mathrm{ppm}(-19.75 \%), 6 \mathrm{~L} / \mathrm{min}$ at $5 \mathrm{ppm}$ $(-41.48 \%)$, and $8 \mathrm{~L} / \mathrm{min}$ at $5 \mathrm{ppm}(-11.0 \%)$.

There were differences in mean airway pressure between baseline and the different NO levels for all nasal CPAP and NIV testing conditions $(P<.05)$ (Fig. 7), except for bubble CPAP $(P=.65)$. Pressures during INO therapy were within $5 \%$ of the baseline measurements for each of the noninvasive devices tested.

\section{Discussion}

The major findings of this study include the following. (1) The accuracy of NO delivery was within the stated 


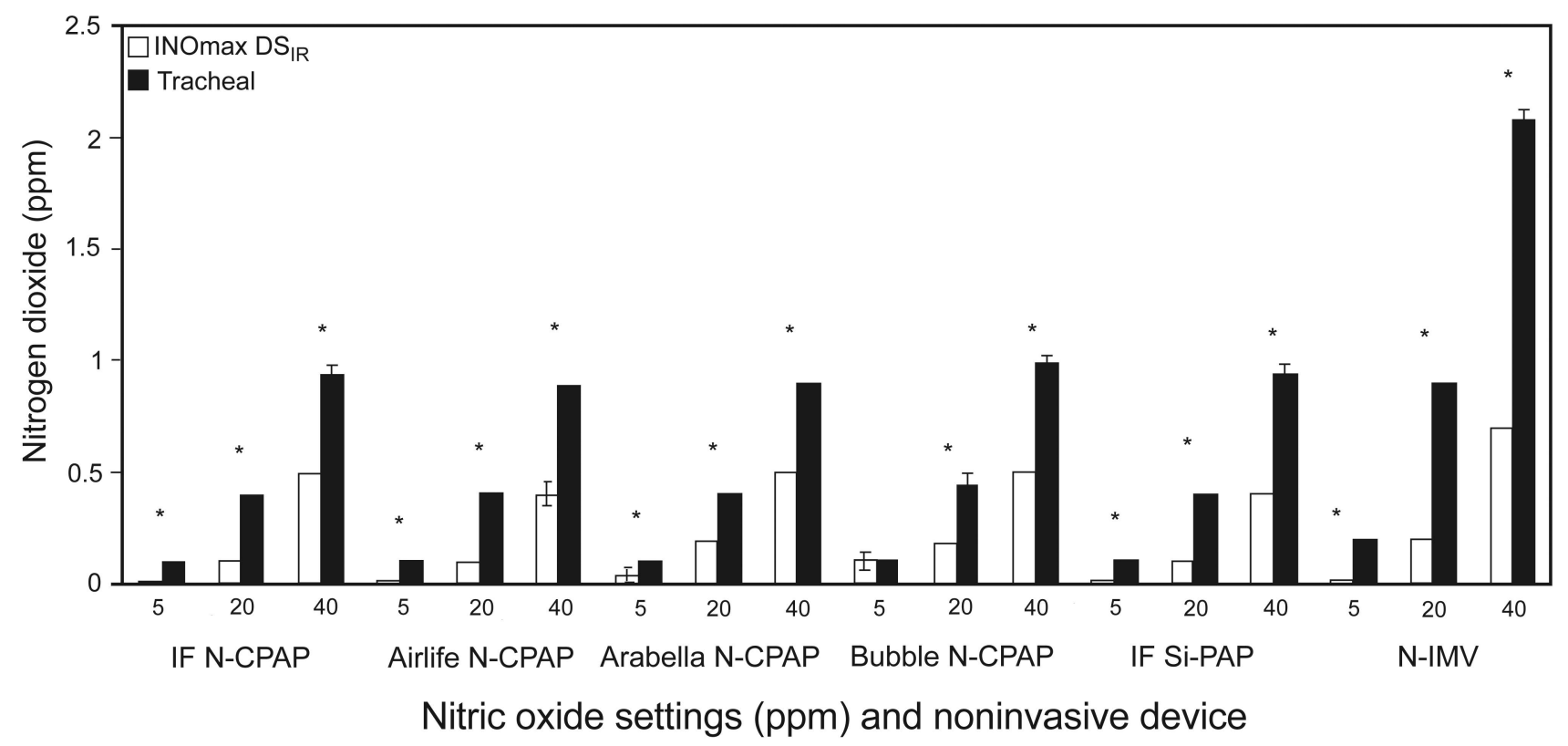

Fig. 5. Nitrogen dioxide levels with nasal CPAP (N-CPAP) and noninvasive ventilation devices. Data are shown as mean \pm SD. ${ }^{*} P<.001$. IF = Infant Flow; Si-PAP = sigh positive airway pressure; N-IMV = nasal intermittent mandatory ventilation.

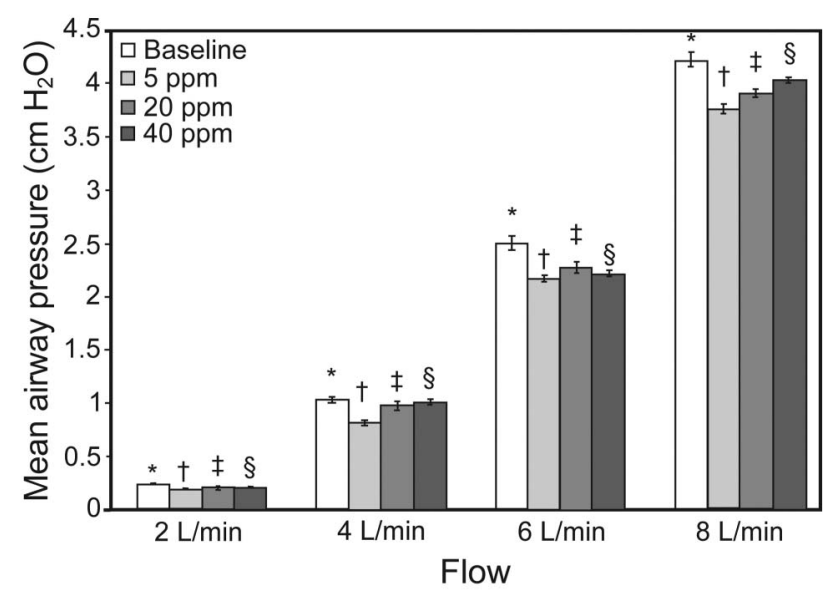

Fig. 6. Mean airway pressure with heated and humidified high-flow nasal cannula. Data are shown as mean \pm SD. Values not sharing common symbols per designated flow are different $(P<.05)$.

accuracy range for all forms of support that used occlusive nasal airway interfaces (nasal CPAP and NIV), but due to the inherent leak during HFNC, the accuracy was outside of the manufacturer's range $(>20 \%)$. The clinically available measurement of INO and $\mathrm{NO}_{2}$, as measured by the INOmax $\mathrm{DS}_{\mathrm{IR}}$, did not consistently reflect the delivered dose of $\mathrm{NO}$ or formation of $\mathrm{NO}_{2}$ in a tracheal airway model in most types of neonatal noninvasive respiratory support. (2) Tracheal $\mathrm{NO}_{2}$ levels were $<1.5 \mathrm{ppm}$ for all forms of noninvasive support, except N-IMV. (3) Lung model mean airway pressures were mildly affected by gas sampling/delivery during combined INO therapy/HFNC at certain flows but remained stable with all other forms of noninvasive support.

Lindwall et al reported in 2 separate bench studies, ${ }^{21,22}$ followed by a clinical study, ${ }^{7}$ that INO can be delivered safely and effectively using a modified continuous-flow titration INO delivery system with the Infant Flow nasal CPAP system. Trevisanuto et al evaluated the feasibility of INO therapy using a neonatal CPAP helmet in a bench study, ${ }^{23}$ followed by a case report ${ }^{24}$ describing the successful application in the long-term treatment of an infant with pulmonary hypertension. INO therapy appeared feasible with that system and was found to be an effective treatment option in one subject. However, INO therapy was provided with antiquated continuous-flow NO titration systems, and these bench studies did not use a realistic lung model or fast-response NO analyzer. Since the time of these bench studies, FDA-approved INO delivery systems have continuously improved. Likewise, a number of noninvasive devices, other than nasal CPAP, have been introduced to the market. The current study was designed to provide a realistic clinical/physiologic environment by using a current FDA-approved INO delivery device, a nitric oxide-consuming filter, fast-response and highly accurate NO sensors, and a realistic nasal airway attached to a spontaneously breathing lung model using multiple noninvasive devices.

NO delivery was within the suggested accuracy range using all nasal CPAP/NIV devices. We believe that the major influence on accuracy with these devices was due to the occlusive nature of the nasal prongs. Although we 


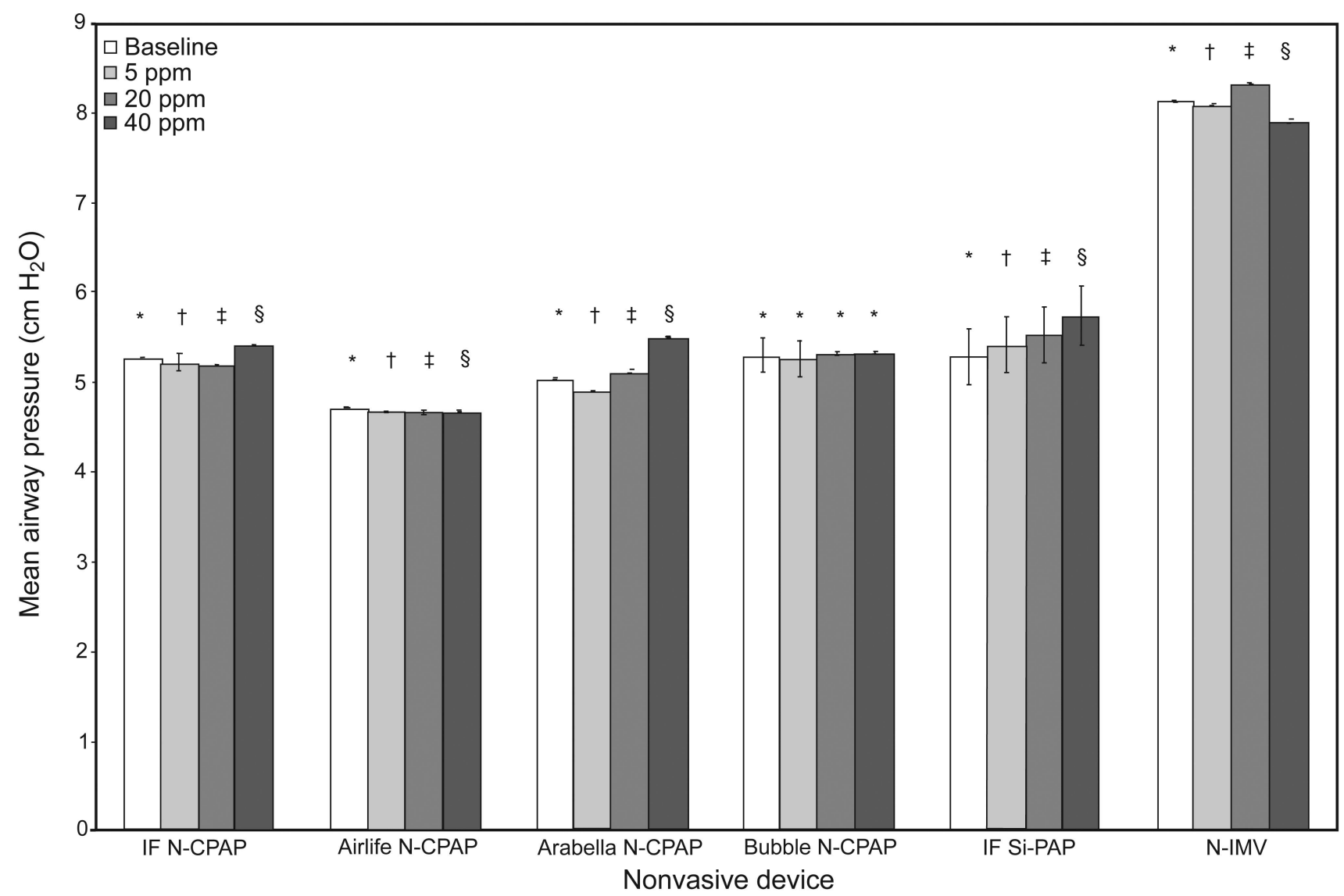

Fig. 7. Mean airway pressure with nasal CPAP (N-CPAP) and noninvasive ventilation devices. Data are shown as mean \pm SD. Values not sharing common symbols per designated flow are different $(P<.05)$. IF = Infant Flow; Si-PAP $=$ sigh positive airway pressure; $\mathrm{N}$-IMV $=$ nasal intermittent mandatory ventilation.

cannot guarantee that these systems were air-tight, measures were used to ensure that similarly sized outer diameter prongs were used with each of the noninvasive devices and that they were fitted snuggly into the nasal airway opening. We postulate that the small differences that were observed between preset and measured NO concentrations are best explained by differences in the accuracy of the electrochemical and chemiluminescence analyzers. Tracheal $\mathrm{NO}_{2}$ accumulation and consequent dilution of tracheal NO may also help to describe why there were differences between NO concentrations measured in the 2 locations, regardless of the device being used. For example, differences in the INOmax $\mathrm{DS}_{\mathrm{IR}}$ and tracheal NO was negligible when 5 ppm was used because $\mathrm{NO}_{2}$ was nearly absent at the tracheal level. As the dose increased from 20 to $40 \mathrm{ppm}$, not only did the $\mathrm{NO}_{2}$ levels increase, but in most cases, the disparity between the $2 \mathrm{NO}$ measurements increased. Although we did not test the hypothesis that there were differences in NO delivery between the different nasal CPAP/NIV devices, the respective values of the preset INO dose and tracheal NO concentrations were similar at the respective NO settings between devices. As such, the specialized gas flow pathways during each form of noninvasive support do not appear to be a contributing factor for the accuracy of INO delivery in this lung model.

We speculate that the major reason for the observed disparities between preset and measured NO concentrations during HFNC is due to entrainment of ambient air around the non-occlusive prongs. This leak accounted for nearly a $50 \%$ reduction in tracheal $\mathrm{NO}$ at flows $\leq 4 \mathrm{~L} / \mathrm{min}$ at the different NO settings. Differences in NO accuracy can also be explained, with all devices and INO settings, by the dilution effects of $\mathrm{NO}_{2}$ mixing at the tracheal level, especially when higher INO concentrations were used. Our findings with HFNC are consistent with those reported by Kinsella et al, ${ }^{5}$ who obtained posterior pharyngeal INO measurements using a chemiluminescence analyzer in postsurgical congenital diaphragmatic hernia subjects receiving INO via a nasal cannula. The authors concluded that nasopharyngeal NO concentrations were $5.4 \pm 0.5$ and $2.4 \pm 0.4 \mathrm{ppm}$ with inhaled NO doses of 10 and $5 \mathrm{ppm}$, respectively. Although these authors used much lower flows with a standard (non-heated/humidified) oxygen cannula during INO administration, we observed a mean value for 
all HFNC testing that was also $\sim 40 \%$ lower than the preset NO level. Of particular interest, we found that increasing flow by $>2 \mathrm{~L} / \mathrm{min}$ during HFNC reduced ambient gas entrainment and thus dilutional effects of $\mathrm{NO}$, resulting in less disparity between the preset and delivered doses. On the basis of these data, patients who exhibit poor clinical response to INO therapy may benefit from using higher flows during HFNC. This may serve as an alternative to titration of the INO or $\mathrm{F}_{\mathrm{IO}_{2}}$ levels for improved clinical response. Additionally, transitioning to a noninvasive device that uses more occlusive nasal prongs might be another feasible option, but only if this benefit is weighed against the potential risk associated with reduced pulmonary blood flow secondary to increased alveolar pressures.

The $\mathrm{NO}_{2}$ levels measured from within the patient circuit poorly reflected the actual delivered tracheal $\mathrm{NO}_{2}$ dose during all forms of noninvasive support. In fact, we observed that in most devices, tracheal $\mathrm{NO}_{2}$ may be 2-4 times greater than the measured value on the INOmax $\mathrm{DS}_{\text {IR }}$. There is potential for $\mathrm{NO}_{2}$ to form in the patient circuit distal to the sampling site and nasal airway interface, but we suspect that these differences are best explained by $\mathrm{NO}_{2}$ accumulation within the simulated nasal airway and trachea. The relatively large dead space of the infant's nasal airway and trachea may serve as a reservoir for $\mathrm{NO}$ and $\mathrm{O}_{2}$ to react to form $\mathrm{NO}_{2}$. Although this becomes less of an issue during invasive mechanical ventilation (because the upper airway and a portion of the trachea are bypassed with an endotracheal tube), it is an important consideration when using any noninvasive device with INO therapy. Using $\mathrm{F}_{\mathrm{IO}_{2}}$ of 1.0 most likely contributed to the measured $\mathrm{NO}_{2}$ levels as well, and it would be reasonable to assume that lower levels will be seen at a lower $\mathrm{F}_{\mathrm{IO}_{2}}$.

As mention previously, $\mathrm{NO}_{2}$ is a toxic gas, and the Occupational Safety and Health Administration recommends that human peak exposure levels remain $<5$ ppm. ${ }^{25}$ In animal studies, inhaled $\mathrm{NO}_{2}$ at $\sim 2 \mathrm{ppm}$ affected alveolar development and surfactant production, altered the epithelial lining of the terminal bronchioles, and induced loss of cilia. ${ }^{21,26,27}$ In human studies, inhaled $\mathrm{NO}_{2}$ at $\sim 2$ ppm affected alveolar permeability ${ }^{28}$ and increased airway responsiveness. ${ }^{29}$ In another study in humans, alterations of airway reactivity have been reported at exposures as low as $1.5 \mathrm{ppm} \mathrm{NO}_{2}{ }^{30}$

Potentially toxic $\mathrm{NO}_{2}$ levels ( $>2 \mathrm{ppm}$ ) were observed only during N-IMV using $40 \mathrm{ppm}$ NO. It is very unlikely that many infants would be supported clinically with $40 \mathrm{ppm} \mathrm{NO}$ and $\mathrm{F}_{\mathrm{IO}_{2}}$ of 1.0, but nonetheless, this represents a worst case scenario for $\mathrm{NO}_{2}$ to form during noninvasive support. We believe that the observed high $\mathrm{NO}_{2}$ levels during $\mathrm{N}$-IMV are related to the low bias flow ( $2 \mathrm{~L} / \mathrm{min}$ ) used by the Avea ventilator. All other nasal CPAP and noninvasive devices used higher flows $(\sim 8-10$
$\mathrm{L} / \mathrm{min}$ ), and $\mathrm{NO}_{2}$ concentrations never exceeded $1 \mathrm{ppm}$. As such, lower flows may result in a longer dwell time for gases to chemically react and allow $\mathrm{NO}_{2}$ accumulation within the nasal airway model, simulated trachea, and inspiratory limb of the ventilator.

Sokol et al ${ }^{9}$ measured $\mathrm{NO}_{2}$ during simulated neonatal ventilation and found $\mathrm{NO}_{2}$ values of $<1 \mathrm{ppm}$ using $80 \mathrm{ppm}$ with $\mathrm{F}_{\mathrm{IO}_{2}}$ of $\sim 1.0$. They used a pressure-limited timecycled continuous-flow ventilator, and flows are generally set between 8 and $10 \mathrm{~L} / \mathrm{min}$ in these ventilators. The nasal CPAP/NIV devices other than N-IMV used in the current study were preset with flows of $\sim 8-10 \mathrm{~L} / \mathrm{min}$. Although we used $40 \mathrm{ppm}$ as the maximum $\mathrm{NO}$ setting, $\mathrm{NO}_{2}$ was $<1 \mathrm{ppm}$ with all testing conditions.

Lindberg and Rydgren ${ }^{12}$ demonstrated for one ventilator that uses bias flows of $<2 \mathrm{~L} / \mathrm{min}$ that even small changes in system dead space can result in considerable changes in $\mathrm{NO}_{2}$ formation during $\mathrm{NO}$ delivery. They found that insertion of an empty humidifier in the inspiratory limb increased the concentration of $\mathrm{NO}_{2}$ from 4.9 to $8.1 \mathrm{ppm}$ (using $80 \mathrm{ppm} \mathrm{NO}$ ). When the humidifier was filled with water, $\mathrm{NO}_{2}$ decreased to $6.6 \mathrm{ppm}$. They also observed greater $\mathrm{NO}_{2}$ concentrations as the ventilatory flows were decreased. This supports the finding from the current study that dead space from the nasal airway model, combined with low bias flows, increases residence time for $\mathrm{NO}_{2}$ and $\mathrm{O}_{2}$ during exhalation, resulting in a bolus of inhaled $\mathrm{NO}_{2}$ during simulated N-IMV. It was interesting to note that $\mathrm{NO}_{2}$ concentration was $<1 \mathrm{ppm}$ with $\mathrm{HFNC}$ at $2 \mathrm{~L} / \mathrm{min}$ and $40 \mathrm{ppm}$. Because this device uses a monophasic flow, it is likely that fresh gas penetrated the anatomic dead space of the nasal airway model, and $\mathrm{NO}_{2}$ was eliminated through the nasal airway leak.

We report for the first time pressures obtained from within a spontaneously breathing neonatal lung model with combined noninvasive/INO therapy. As mentioned previously, the INOmax $\mathrm{DS}_{\mathrm{IR}}$ adds gas proportional to the INO setting and the measured flows being generated by the noninvasive device. Conversely, the INO-monitoring system subtracts volume from inspired gases at a rate of $230 \mathrm{~mL} / \mathrm{min}$. According to the INOmax DS $\mathrm{IR}_{\mathrm{IR}}$ operator's manual, the approximate amount of INO flow added to the system when using $20 \mathrm{ppm}$ at $10 \mathrm{~L} / \mathrm{min}$ is $250 \mathrm{~mL} / \mathrm{min}$. This would account for a net gain of gas of $\sim 20 \mathrm{~mL} / \mathrm{min}$ being added to the system. At the lower NO settings, less NO gas is added to the system, but the gas sampling rate is fixed at $230 \mathrm{~mL} / \mathrm{min}$. Conversely, $\mathrm{NO}$ settings greater than $20 \mathrm{ppm}$ at $10 \mathrm{~L} / \mathrm{min}$ add $>250 \mathrm{~mL} / \mathrm{min} \mathrm{NO}$ to the system. As such, sampling at lower NO settings could affect lung recruitment by reducing the mean airway pressure. Adding additional gases to the system at higher NO settings could increase mean airway pressure and place infants at greater risk for lung injury. We found that gas sampling affects mean airway pressure levels during HFNC, 
especially at flows of $>4 \mathrm{~L} / \mathrm{min}$, but there did not appear to be a large effect when using other forms of noninvasive support.

Although we did not observe major differences in pressure related to INO therapy, it is still necessary to continuously monitor the ventilation system for disparities between the set and measured parameters before and after implementation of INO therapy and with changes in the INO settings.

\section{Limitations}

In this in vitro study, we took careful measures to simulate a realistic neonatal clinical environment. We used modern noninvasive respiratory support devices, a heated humidifier, a realistic nasal airway model, a filter that consumed $\mathrm{NO}$ and $\mathrm{NO}_{2}$ similar to the human lung, and an actively breathing test lung configured with mechanics similar to those measured in neonates. However, like all data obtained from studies in vitro, the results must be approached with some trepidation. We used only one lung model configuration and settings that are commonly used with noninvasive devices. We did not test the range of settings that are commonly used. It is possible that different support settings and lung mechanics configurations could render different results. Furthermore, we used a chemiluminescence analyzer that sampled gas from the simulated neonatal trachea. It is quite possible that this sampling may have entrained room air around the nonocclusive prongs with HFNC, resulting in potentially lower tracheal NO levels than those that would be delivered under ideal physiologic conditions (without an analyzer). Because this testing included only a simulated nasal airway, all delivered gas concentrations could be grossly overestimated because an oral leak was not present in this model. As such, it should be assumed that in the presence of an oral leak during noninvasive/INO therapy, entrainment/dilution by ambient air will reduce the $\mathrm{NO} / \mathrm{NO}_{2} \mathrm{lev}$ els to the patient. Finally, we tested only FDA-approved neonatal noninvasive devices because INO is FDAapproved only in neonates at $>34$ weeks of gestation. Clinicians should not extrapolate from these data and expect similar results in a larger pediatric or adult lung model using INO with approved noninvasive devices used in this population. Future studies enrolling live subjects need to be conducted to determine whether these findings are similar.

\section{Conclusions}

On the basis of these findings, clinicians cannot assume that the NO level set on the INO delivery system will always result in a similar dose being applied to patients when using all forms of neonatal noninvasive support. Leak at the nasal airway interface may be a major limiting factor for neonates receiving the desired INO dose with any noninvasive device. HFNC is intended to be used as an inherently leaky device, and disparities between the preset and delivered INO levels are always likely to exist. Clinical decisions regarding ways to improve INO delivery may need to include manipulating noninvasive settings, minimizing leak, or placing patients on a different form of support. The $\mathrm{NO}_{2}$ level delivered to the patient could be greater than the value recorded by the INO delivery system because the nasal airway interface and nasal airway serve as additional reservoirs for oxygen to combine with NO, particularly at $\mathrm{F}_{\mathrm{IO}_{2}}$ of 1.0. Pressures are relatively unaffected with most forms of noninvasive support combined with INO therapy. Although pressures are typically not monitored during HFNC, INO therapy sampling at higher flows may affect delivered pressures.

\section{REFERENCES}

1. DiBlasi RM, Myers TR, Hess DR. Evidence-based clinical practice guideline: inhaled nitric oxide for neonates with acute hypoxic respiratory failure. Respir Care 2010;55(12):1717-1745.

2. Muscedere JG, Mullen JB, Gan K, Slutsky AS. Tidal ventilation at low airway pressures can augment lung injury. Am J Respir Crit Care Med 1994;149(5):1327-1334.

3. Ricard JD, Dreyfuss D, Saumon G. Ventilator-induced lung injury. Eur Respir J 2003;22(Suppl 42):2S-9S.

4. de Waal K, Evans N, van der Lee J, van Kaam A. Effect of lung recruitment on pulmonary, systemic, and ductal blood flow in preterm infants. J Pediatr 2009;154(5):651-655.

5. Kinsella JP, Parker TA, Ivy DD, Abman SH. Noninvasive delivery of inhaled nitric oxide therapy for late pulmonary hypertension in newborn infants with congenital diaphragmatic hernia. J Pediatr 2003; 142(4):397-401.

6. Welzing L, Bagci S, Abramian A, Bartmann P, Berg C, Mueller A. CPAP combined with inhaled nitric oxide for treatment of lung hypoplasia and persistent foetal circulation due to prolonged PPROM. Early Hum Dev 2011;87(1):17-20.

7. Lindwall R, Blennow M, Svensson M, Jonsson B, Berggren-Boström E, Flanby M, et al. A pilot study of inhaled nitric oxide in preterm infants treated with nasal continuous positive airway pressure for respiratory distress syndrome. Intensive Care Med 2005;31(7):959964.

8. Ballard RA, Truog WE, Cnaan A, Martin RJ, Ballard PL, Merrill JD, et al. Inhaled nitric oxide in preterm infants undergoing mechanical ventilation. N Engl J Med 2006;355(4):343-353.

9. Sokol GM, Van Meurs KP, Wright LL, Rivera O, Thorn WJ 3rd, Chu PM, Sams RL. Nitrogen dioxide formation during inhaled nitric oxide therapy. Clin Chem 1999;45(3):382-387.

10. Kirmse M, Hess D, Fujino Y, Kacmarek RM, Hurford WE. Delivery of inhaled nitric oxide using the Ohmeda INOvent Delivery System. Chest 1998;113(6):1650-1657.

11. Young JD, Roberts M, Gale LB. Laboratory evaluation of the I-NOvent nitric oxide delivery device. Br J Anaesth 1997;79(3):398-401.

12. Lindberg L, Rydgren G. Production of nitrogen dioxide during nitric oxide therapy using the Servo Ventilator 300 during volume-controlled ventilation. Acta Anaesthesiol Scand 1999;43(3):289-294.

13. DiBlasi RM, Richardson CP, Hansen T. Pulmonary physiology of the newborn. In: Gleason A, Devasker S. Avery's diseases of the newborn, 9th edition. Philadelphia: Saunders; 2012:44-1-44-13. 


\section{Nitric Oxide Delivery by Neonatal Noninvasive Respiratory Support Devices}

14. Youngquist TM, Richardson CP, Diblasi RM. Effects of condensate in the exhalation limb of neonatal circuits on airway pressure during bubble CPAP. Respir Care 2013;58(11):1840-1846.

15. Yang CL, Chen L. Oxidation of nitric oxide in a two-stage chemical scrubber using dc corona discharge. J Hazard Mater 2000;80(1-3): 135-146.

16. Poulton BB, Foubert L, Klinowski J, Latimer RD, Knowles PR, Vuylsteke A. Extraction of nitric oxide and nitrogen dioxide from an oxygen carrier using molecular sieve 5A. Br J Anaesth 1996;77(4): 534-536.

17. Diblasi RM. Nasal continuous positive airway pressure (CPAP) for the respiratory care of the newborn infant. Respir Care 2009;54(9): 1209-1235.

18. INOmax $\mathrm{DS}_{\mathrm{IR}}$ operator's manual. http://inomax.com/inomaxdelivery-systems/inomax-dsir/support-resources. Accessed February 10, 2014.

19. Hudome SM, Ergenekon EN, Darrow KA, Richard RB, Snider MT, Marks KH. Precise control of nitric oxide concentration in the inspired gas of continuous flow respiratory devices. Pediatr Pulmonol 1996;22(3):182-187.

20. Betit P, Adatia I, Benjamin P, Thompson JE, Wessel DL. Inhaled nitric oxide evaluation of a continuous titration delivery technique for infant mechanical ventilation and manual ventilation. Respir Care 1995;40(7):706-715.

21. Lindwall R, Frostell CG, Lönnqvist PA. Delivery characteristics of a combined nitric oxide nasal continuous positive airway pressure system. Paediatr Anaesth 2002;12(6):530-536.

22. Lindwall R, Svensson ME, Frostell CG, Eksborg S, Gustafsson LE. Workplace $\mathrm{NO}$ and $\mathrm{NO}_{2}$ during combined treatment of infants with nasal CPAP and NO. Intensive Care Med 2006;32(12):20342041.

23. Trevisanuto D, Doglioni N, Micaglio M, Zanardo V. Feasibility of nitric oxide administration by neonatal helmet-CPAP: a bench study. Paediatr Anaesth 2007;17(9):851-855.

24. Doglioni N, Micaglio M, Zanardo V, Trevisanuto D. Long-term use of neonatal helmet-CPAP: a case report. Minerva Anestesiol 2009; 75(12):750-753.

25. Centers for Disease Control (CDC). NIOSH recommendations for occupational safety and health standards 1998. MMWR Morbid Mortal Wkly Rep 1988;37(Suppl 7):1-29.

26. Stephens RJ, Freeman G, Evans MJ. Early response of lungs to low levels of nitrogen dioxide. Light and electron microscopy. Arch Environ Health 1972;24(3):160-179.

27. Evans MJ, Stephens RJ, Cabral LJ, Freeman G. Cell renewal in the lungs of rats exposed to low levels of $\mathrm{NO}_{2}$. Arch Environ Health 1972;24(3): 180-188.

28. Rasmussen TR, Kjaergaard SK, Tarp U, Pedersen OF. Delayed effects of $\mathrm{NO}_{2}$ exposure on alveolar permeability and glutathione peroxidase in healthy humans. Am Rev Respir Dis 1992;146(3):654599.

29. Bylin G, Lindvall T, Rehn T, Sundin B. Effects of short-term exposure to ambient nitrogen dioxide concentrations on human bronchial reactivity and lung function. Eur J Respir Dis 1985;66(3):205-217.

30. Frampton MW, Morrow PE, Cox C, Gibb FR, Speers DM, Utell MJ. Effects of nitrogen dioxide exposure on pulmonary function and airway reactivity in normal humans. Am Rev Respir Dis 1991;143(3): 522-527. 